\title{
Articulação teórica entre registros de representação semiótica e Etnomatemática: no contexto da prática de pesca artesanal
} A theoretical relationship between registers of semiotic representation
theory and Ethnomatematics: in the context of artisanal fishing practice

\author{
Deusarino Oliveira Almeida Júnior ${ }^{1}$ \\ José Messildo Viana Nunes² \\ Fábio José da Costa Alves ${ }^{3}$ \\ Kayla Rocha Braga ${ }^{4}$ \\ Carlos Alberto Gaia Assunção ${ }^{5}$
}

\section{Resumo}

O estudo foi desenvolvido a partir do contexto da pesca artesanal praticada no município de Vigia de Nazaré PA. A intervenção procedeu-se com alunos egressos do $9^{\circ}$ ano do Ensino Fundamental, com objetivo de contextualizar o estudo de proporção às práticas laborais da pesca por meio da conjunção de ideias da Etnomatemática, no sentido da Etnocomunidade e da Teoria dos Registros de Representação Semiótica - TRRS. A pesquisa de abordagem qualitativa do tipo etnográfica apresenta como instrumento de produção de dados os registros escritos produzidos pelos alunos durante a realização das tarefas que foram concebidas e, posteriormente suas resoluções analisadas fundamentadas pela conjunção entre os campos teóricos adotados. Os resultados obtidos permitiram-nos concluir que as atividades realizadas propiciaram a aprendizagem de conhecimentos relacionados à noção de proporção e revelou indícios de desenvolvimento na capacidade dos alunos em perceber aspectos socioculturais e econômicos de sua realidade. A articulação e o diálogo entre os aportes teóricos comportaram uma síntese indicadora do contexto sociocultural e político institucional nas práticas de pesca, podendo com isso, evidenciar a relação entre práticas sociais e o saber matemático de um grupo cultural específico, aqui entendido como Etnocomunidades.

Palavras chave: raciocínio proporcional; etnocomunidade; pesca artesanal.

\section{Abstract}

The study was developed based on the context of artisanal fishing practiced in the municipality of Vigia de Nazaré - PA. The intervention took place with students who have graduated from the 9th grade of elementary school, with the objective of contextualizing the study of proportion to the labor practices of fishing from the conjunction of ideas of ethnomathematics, in the sense of Ethnocommunity and the Registers of Semiotic Representation Theory. The research of qualitative approach of the ethnographic type, presents as data production instrument, the written records produced by the students during the accomplishment of the tasks that were conceived and later their resolutions analyzed founded by the conjunction between the adopted theoretical fields. The results obtained allowed us to conclude that the activities carried out enabled the learning of knowledge related to the notion of proportion and revealed signs of development in the students' ability to perceive socio-cultural and economic aspects of their reality. The articulation and dialogue between the theoretical contributions involved a synthesis that indicates the socio-cultural and political institutional context in

\footnotetext{
${ }^{1}$ Secretaria de Estado de Educação do Pará | djralmeida@gmail.com

2 Universidade Federal do Pará | messildo@ufpa.br

${ }^{3}$ Universidade do Estado do Pará | fjca@uepa.br

${ }^{4}$ Universidade Federal do Maranhão | kayllabrasil@hotmail.com

${ }^{5}$ Universidade Federal do Sul e Sudeste do Pará | carlosgaia@unifesspa.edu.br
} 
fishing practices, thus making it possible to excel the relationship between social practices and the mathematical knowledge of a specific cultural group understood here as ethnocommunities.

Keywords: proportional reasoning; ethnocommunity; artisanal fishing.

\section{Introdução}

A presente pesquisa versa sobre o ensino de Matemática no contexto da pesca artesanal realizada no município de Vigia de Nazaré - PA. Nessa perspectiva, entendemos que a pesca artesanal, que é desenvolvida atualmente no município citado, configura-se em um tema eminentemente fecundo para o desenvolvimento de diversas pesquisas nos âmbitos educacional, social, cultural e econômico. Assim, em consonância com essa ideia, a pesca artesanal constitui-se em um tema muito pertinente para ser abordado em sala de aula no ensino de Matemática, pois observamos claramente a identificação, mesmo que indireta, dos alunos com a atividade pesqueira no seu cotidiano, a importância dessa atividade na economia da cidade e sua relevância histórica no desenvolvimento do município.

Para construirmos um entendimento sobre esse contexto sociocultural, assumimos que a prática por ora enfocada está inserida nas dimensões política e educacional da Etnomatemática ${ }^{6}$ (D'AMBROSIO, 1990, 2001, 2002). Essa última, nesse contexto, agrega a noção de Etnocomunidade: Uma abordagem sobre as práticas sociais de grupos culturais instituídos e reconhecidos socialmente. Isto é, um enfoque sociológico do saber matemático na tentativa de entender as práticas com matemáticas dentro de um contexto cultural.

Todo tipo de atividade humana encontra-se encapsulada em si mesma, ainda que sejam estabelecidas relações com outras atividades humanas. 0 mesmo ocorre com a atividade educacional escola, (...) que consiste em flashes de jogos de memória discursiva produzidos por diferentes comunidades de prática, sob as quais recaem as práticas de problematização. Nestas condições, a prática de problematização se torna constituinte da etnia (vinculação cultural) e da escola da etnocomunidade. (...) Isso significa que, para a etnocomunidade educacional escolar, as práticas culturais científicas não deveriam desfrutar de antemão de nenhum privilégio epistemológico ou político absoluto em relação às práticas realizadas por outras etnocomunidades. (MIGUEL; MENDES, 2010, p. 22).

Segundo Miguel e Mendes (2010), a educação escolar deveria ter como propósito a preparação das pessoas para a problematização de todas as formas de vida pública. Nessa perspectiva, é que focalizamos o contexto da prática da pesca artesanal para o saber matemático na intenção de agregar essa circunstância extraescolar no ensino da matemática.

\footnotetext{
${ }^{6}$ A Etnomatemática, aqui agrega a noção de Etnocomunidade. "Uma abordagem sobre as práticas sociais de grupos culturais instituídos e reconhecidos socialmente. Isto é, um enfoque sociológico do saber matemático na tentativa de entender as práticas com matemáticas dentro de um contexto cultural". (GAIA, 2012, p. 17).
} 
Essa compreensão favorece a identificação, a discussão e a utilização de situaçõesproblemas relacionadas à pesca, repletas de aspectos próprios que podem ser muito bem adaptadas para sala de aula. Dessa forma, o aluno pode desenvolver, a partir dos conhecimentos matemáticos adquiridos, um olhar mais crítico sobre sua realidade, reconhecendo-se como um sujeito transformador de sua própria realidade e história.

Portanto, os custos relativos a uma viagem de pesca realizada por uma embarcação de pequeno porte, as relações de trabalho que são estabelecidas comumente entre donos de embarcações e tripulação, a importância da pesca artesanal na economia do município, a preservação das espécies marinhas e do meio ambiente, em consequência da pesca de arrastão, que muitas vezes acontecem indiscriminadamente em alto mar sem a devida fiscalização, representam alguns exemplos de situações que podem ser abordadas e discutidas em sala de aula a partir da pesca artesanal realizada em Etnocomunidades, como a que abordamos aqui.

O município de Vigia de Nazaré é fortemente caracterizado pela pesca desenvolvida na cidade. Situado às margens do rio Guajará Mirim, apresenta fácil acesso ao Oceano Atlântico, favorecendo naturalmente a predominância da atividade pesqueira na região. Contempla desde a pesca de mariscos nas beiras do rio mencionado até as que são exercidas por enormes embarcações equipadas com tecnologia de ponta, as quais partem oceano afora para a captura do pescado.

Atualmente, a pesca industrial tem se destacada no município. A partir da adoção de práticas inovadoras, da implementação de tecnologias nas embarcações, de uma gestão mais empresarial e dos incentivos recebidos de entidades públicas de financiamento, uma empresa que atua na modalidade citada, vem exercendo a liderança nesse segmento, promovendo um maior dinamismo na economia vigiense, gerando empregos e renda no município.

Nesse contexto, Santos (2008) nos diz que

\begin{abstract}
A atividade pesqueira do município de Vigia de Nazaré tem na inovação um ponto de atratividade e políticas institucionais direcionadas para a criação de um ambiente favorável ao processo de desenvolvimento do setor. [...] pode-se dizer que a pesca no município de Vigia de Nazaré é um aglomerado produtivo local com caráter inovador (APL(i)), o que permite prever que $\mathrm{O}$ ambiente institucional se desenvolverá e potencializará o seu desempenho. (SANTOS, 2008).
\end{abstract}

Nesse tipo de pesca, utilizam-se grandes embarcações equipadas com vários aparelhos de navegação que permitem localizar os cardumes com maior precisão em alto mar. No entanto, nessa modalidade de pesca pratica-se a técnica do arrasto, que consiste em puxar a certa velocidade, uma pesada rede com o auxílio de duas barcas emparelhadas, recolhendo tudo que estiver em seu caminho. Dessa forma, servem para capturar adequadamente peixes maiores, porém deslocam também aqueles muito pequenos que ainda estão em desenvolvimento, podendo interferir na reprodução das espécies.

Diante disso, verificamos que, se por um lado a inovação e a modernização da pesca podem promover o desenvolvimento econômico de uma região, por outro podem trazer sérios danos ambientais. Ademais, a intensidade com a que a pesca de arrastão vem sendo exercida, a pesca praticada no período do defeso e a utilização de redes com malhas inadequadas, podem estar associadas à escassez de algumas espécies na região. 
Apesar do destaque econômico atribuído à pesca industrial, abordaremos em nosso estudo, o contexto da pesca artesanal exercida no município de Vigia de Nazaré, por meio de embarcações de pequeno porte. Nessa perspectiva, buscamos articular tarefas escolares com as práticas extraescolares da Etnocomunidade da zona pesqueira aqui enfocada. Com objetivo de contextualizar o estudo de proporção às práticas laborais da pesca a partir da conjunção de ideias da Etnomatemática, no sentido da Etnocomunidade, e da Teoria dos Registros de Representação Semiótica.

\section{Breve panorama de pesquisas correlatas}

Com a intenção de buscar subsídios para o desenvolvimento de nossa pesquisa, procuramos realizar um levantamento bibliográfico sobre produções científicas já realizadas, relacionadas ao ensino de matemática no contexto da pesca artesanal.

O levantamento em questão foi realizado no site do Google Acadêmico ${ }^{7}$, por disponibilizar aos usuários ferramentas eficientes de busca adequadas às nossas pretensões, e no site da Biblioteca Digital Brasileira de Teses e Dissertações - BDTD ${ }^{8}$, por se tratar de um repositório específico de dissertações e teses nacionais. Nossa pesquisa inicial não buscou definir um período histórico específico, no entanto, buscamos selecionar aqueles trabalhos mais alinhados com o tema de nosso estudo.

Utilizamos como metodologia de busca, uma revisão sistemática da literatura de acordo com quatro etapas. Na primeira etapa denominada formulação da pergunta, procuramos estabelecer as palavras-chave que seriam utilizadas em consonância com o tema de nosso estudo. Na segunda etapa chamada protocolo de revisão, estabelecemos os critérios utilizados para a inclusão ou exclusão dos trabalhos encontrados. Em seguida, na terceira etapa, realizamos a busca em si com base nas palavras-chave definidas anteriormente. Na última etapa, fizemos uma síntese dos dados obtidos e tecemos algumas conclusões sobre os resultados encontrados nos trabalhos selecionados.

Assim, estabelecemos na primeira etapa as seguintes palavras-chave: "pesca artesanal e matemática", "matemática e pesca" e "ensino de matemática e pesca" e, aplicando-as aos sites mencionados, obviamente, que os resultados encontrados precisavam ser filtrados.

Destarte, nosso filtro inicial consistiu-se em selecionar os trabalhos por seus títulos, de modo que estivessem próximos de nosso estudo. Em seguida, aplicamos um segundo filtro que se fundamentava em ler os respectivos resumos desses trabalhos, refinando ainda mais nossa busca. O próximo filtro aplicado baseou-se em ler a introdução e a conclusão dos trabalhos, obtendo-se uma ideia mais precisa acerca dos trabalhos. Finalmente, obtemos uma relação de 12 trabalhos que foram lidos e analisados em sua totalidade, proporcionando pontos de referência para nossa pesquisa e embasando posteriormente nossas discussões finais.

\footnotetext{
${ }^{7}$ O Google Scholar ou Acadêmico é uma ferramenta de pesquisa do Google que permite pesquisar trabalhos acadêmicos, literatura escolar, jornais de universidades e artigos variados.

${ }^{8}$ O BDTD, integra e dissemina em um só portal de busca, os textos completos das teses e dissertações defendidas nas instituições brasileiras de ensino e pesquisa.
} 
Refletindo sobre os resultados de nosso estudo bibliográfico, observamos que (dez dos doze trabalhos analisados), ou seja, mais de $80 \%$ deles, são desenvolvidos considerando-se enfaticamente a realidade em que o aluno está inserido, na etapa de elaboração das propostas da investigação.

Em decorrência desses dados, ressaltamos que aproximadamente 85\% dos trabalhos analisados (dez trabalhos) usam a Modelagem Matemática como base teóricometodológica e 15\% deles (dois trabalhos) utilizam outro quadro teórico. Trata-se dos estudos de Pinheiro, Alves e Silva (2016) e de Schönardie (2011).

O primeiro deles recorre à Semiótica de Raymond Duval para analisar os registros de representação semiótica em uma atividade matemática desenvolvida com alunos ribeirinhos. Esse trabalho aproxima-se do que pretendemos realizar em nossa pesquisa, já que investiga as representações produzidas pelos alunos com o intuito de averiguar indícios de aprendizagem. Logo, Almeida et al nos diz que,

[...] A construção desses conhecimentos está ancorada em uma variedade de representações semióticas que incorporam características do objeto matemático representado, objeto matemático este que, enquanto ideia, só se torna acessível e comunicável por meio dessa representação. (ALMEIDA et al., 2016, p. 35)

O segundo trabalho adota como base metodológica a Modelagem Matemática e a Educação Matemática Crítica de Ole Skovsmose caracterizadas como aquelas em que os professores e alunos se envolvem conjuntamente no processo educacional por meio do diálogo, a fim de desenvolver a democratização do poder. Entendemos que essa perspectiva favorece o desenvolvimento de metodologias não tradicionais, e que por sua vez, favorece a participação efetiva do aluno na construção de conhecimentos a partir das atividades planejadas, alinhando-se com o que aspiramos em nossa proposta para este estudo.

Diante da análise dos trabalhos selecionados, verificamos que a inclusão de imagens da realidade para ilustrar uma ideia expressa no texto que compõe uma atividade, aguça um olhar mais atento do aluno para sua própria realidade, podendo se expandir para uma visão mais crítica através da apreensão de conhecimentos matemáticos que vão sendo adquiridos.

Nossa pesquisa busca contribuir nesse quadro de pesquisa sobre o ensino de matemática e o contexto das práticas de pesca de determinada Etnocomunidade. Para tal, fundamentamo-nos em princípios teóricos da Teoria de Registro de Representação Semiótica articulada a ideias presentes no programa Etnomatemática.

\section{A teoria dos registros de representação semiótica}

Para Duval (2009, p. 29), "não é possível estudar fenômenos relativos ao conhecimento sem recorrer à noção de representação. [...], não há conhecimento que não possa ser mobilizado por um sujeito sem uma atividade de representação".

Sobre as representações, concebe que

As representações semióticas, ou seja, as produções constituídas pelo emprego de regras de sinais (enunciado em língua natural, fórmula algébrica, gráfico, figura geométrica, ...) parecem apenas ser o meio de 
que o indivíduo dispõe para exteriorizar suas representações mentais, ou seja, para tornarem visíveis ou acessíveis a outro. (DUVAL, 2009, p. 15)

Por conseguinte, os registros escritos produzidos durante uma atividade cognitiva, por exemplo, refletem as concepções do indivíduo sobre o objeto matemático em questão. Isto posto, o objeto matemático não retrata uma "coisa" que possa ser evocada de forma presencial, sendo essencial uma representação semiótica para fazê-lo referência. Assim, nessa semiose, é imprescindível diferenciar o objeto matemático em si de sua representação semiótica para que se possa compreender um objeto matemático. Portanto, essa questão é concernente ao paradoxo cognitivo do pensamento matemático, o qual aponta duas questões fundamentais que apresentam fortes repercussões na aprendizagem do sujeito.

A primeira considera que a percepção de que o objeto matemático em estudo e sua representação semiótica são distintos, não é tão imediata. Isso porque, o objeto matemático (objeto mental) só se relaciona, exclusivamente, por meio de tais representações semióticas.

Sobre isso, Duval apud (D'AMORE, 2015, p.134) nos diz que, "A impossibilidade de um acesso direto aos objetos matemáticos, para além de qualquer representação semiótica, torna a confusão quase inevitável". Corrobora com esta afirmação, o fato de que o primeiro contato do aprendiz não é com o objeto matemático em si, mas com uma representação semiótica particular desse objeto, e ao que parece, esse fato, geralmente não fica elucidado.

Esses obstáculos geram, com o passar do tempo, segundo Duval (2009, p. 14), perda de compreensão, enfatizando que "os conhecimentos adquiridos se tornam então rapidamente inutilizáveis fora de seus contextos de aprendizagem: seja por falta de atenção, seja por eles tornarem-se representações inertes não sugerindo tratamento produtor".

A segunda questão fundamental relacionada ao paradoxo acima faz referência à seguinte indagação: como é possível, ao aprendiz, transitar entre as diferentes representações semióticas possíveis para um determinado objeto matemático, se ainda não possui clareza conceitual do objeto representado?

Bernd (2016) afirma que os registros de representações semióticas proporcionam um olhar atento às recorrentes e necessárias conversões nas formas de representação de objetos matemáticos e a importância destas conversões".

Nessa perspectiva, Duval (2009) desenvolve a Teoria dos Registros de Representação Semiótica na qual trata de discussões dos processos cognitivos da aprendizagem de matemática. Conforme esse autor, faz-se necessário significar representações semióticas de um objeto.

Na matemática, a palavra 'representar' é bastante utilizada para a compreensão dos conceitos matemáticos. Por exemplo, um símbolo 'representa' um objeto matemático pode ser um número, uma função etc. Um traçado 'representa' um objeto matemático pode ser um segmento, um ponto etc. Duval (2012, p. 268) afirma que "a distinção entre um objeto e sua representação é, portanto, um ponto estratégico para a compreensão da matemática". É oportuno dizer que os objetos matemáticos não devem ser confundidos com a representação que se faz dele. Ainda, Duval (2012, p.269) define as representações semióticas como sendo as "produções constituídas pelo emprego de signos pertencentes a um sistema de representações que tem inconvenientes próprios de significação e de funcionamento". Essas representações são essenciais às atividades cognitivas do pensamento. E por isso, desempenham um papel no desenvolvimento das representações mentais, na realização de diferentes funções cognitivas e na produção de conhecimento. 
Ainda segundo Duval (2012), é essencial, na atividade matemática, poder mobilizar muitos registros de representação semiótica (figuras, gráficos, escrituras simbólicas, língua natural etc.) no decorrer de um mesmo passo e escolher um registro no lugar de outro. Ressaltamos que os objetos matemáticos não devem ser confundidos com suas representações, mas devem ser reconhecidos em cada uma delas.

No funcionamento cognitivo do pensamento, destacamos aqui duas noções: semiose (apreensão de uma representação semiótica) e noesis (apreensão conceitual de um objeto). O sistema semiótico para que seja um registro de representação deve permitir três atividades cognitivas ligadas à semiose: A formação de uma representação identificável (como exemplo citamos - desenho de uma figura geométrica, expressão de uma fórmula), essa formação pode ser comparada à realização de uma tarefa de descrição; o tratamento é uma transformação interna a um registro.

Assim, citamos o cálculo que é uma forma de tratamento próprio das expressões simbólicas (cálculo numérico, cálculo algébrico etc.) ou a reconfiguração que é um tipo de tratamento particular para as figuras geométricas: é uma das numerosas operações que dá ao registro das figuras o seu papel heurístico; a conservação é uma transformação externa ao registro de início - o registro da representação a converter. Citamos a descrição que é a conversão de uma representação não verbal (esquema, figura, gráfico) em uma função linguística. Conforme Duval (2009), existem dois tipos de transformações de representações:

- Tratamentos: transformações que ficam dentro do mesmo sistema, como a resolução de uma equação;

- Conversões: transformações que mudam de sistema, mas contemplando o mesmo objeto, como a passagem da linguagem algébrica para a geométrica.

De acordo com o exemplo de Duval (2012, p.273), podemos compreender melhor o que significa Tratamento.

[...] Para a expressão de um número é preciso, de fato, distinguir a significação operatória ligada ao significante, em virtude das regras do sistema de expressão escrita (esta significação operatória não é a mesma para $0,25,1 / 4$ e $25.10^{-2}$ : não são os mesmos tratamentos que devem ser considerados para efetuar as adições $0,25+0,25=0,5,1 / 4+1 / 4=1 / 2 \mathrm{e}$ $25.10^{-2}+25.10^{-2}=50.10^{-2}$ e o número representado que não é o significante 0,25 , nem o significante $1 / 4$ e nem o significante $25.10^{-2}$. Cada uma destas três expressões tem uma significação operatória, mas representa o mesmo número" (grifo nosso).

Destarte, Duval (2009) propõe que a efetiva aprendizagem das propriedades de um objeto ocorre justamente na passagem de um registro para outro, pois as diferentes representações apresentam conteúdos e atributos diferentes sobre um mesmo objeto. E acrescenta quando diz que é necessário utilizar, no mínimo, duas formas distintas de representação: "essa é a única possibilidade de que se dispõe para não confundir o conteúdo de uma representação com o objeto representado" (DUVAL, 2009, p. 22).

Com o intuito de responder ao questionamento: a que corresponde a existência de muitos registros de representação e qual é o interesse de sua coordenação para o funcionamento do pensamento humano? Duval (2012) coloca-nos três respostas. A primeira corresponde à economia de tratamento. O autor enfatiza que essas respostas não se excluem, mas é importante ver que se situam em níveis de descrição diferentes da atividade cognitiva. Posteriormente, decorre cada uma das respostas, explicitando-as: 
A primeira resposta (a economia de tratamento), centrada sobre os custos de tratamento, sustenta-se em uma situação de descrição superficial. Ela se refere ao funcionamento de cada registro tal como é conscientemente vivido no tratamento das representações. A segunda reposta (a complementaridade dos registros), mais semiótica, supõe uma comparação de diferentes modos de representação de um mesmo objeto. Esta comparação requer uma análise de aspectos que são levados em conta e daqueles que não o são em cada registro. A terceira resposta ( $a$ conceitualização implica coordenação de registros de representação) é menos imediatamente acessível, ela supõe uma abordagem desenvolvimentista da atividade cognitiva nas disciplinas em que o recurso a uma pluralidade de registros é fundamental. Ela supõe, além disso, que se substituam, no estudo das aquisições, critérios de "maturidade" (rapidez de tratamento, espontaneidade das conversões, potência das transferências) no lugar de simples critérios de êxitos (obtenção da "boa" resposta). (DUVAL, 2012, p. 278 e 279, grifo nosso).

Na terceira resposta, há uma ideia que é geralmente admitida, sendo possível formulála por meio de duas hipóteses: A primeira delas - se o registro de representação é bem escolhido e se são, suficientes para permitir a compreensão do conteúdo conceitual demonstrado. Contudo, essa hipótese, segundo Duval (2012), parece satisfatória se referida apenas aos pesquisadores ou professores de matemática que apresentam um domínio da atividade matemática, mas não para um aluno que está em processo de aprendizagem. Podemos dizer que aqui, nesta hipótese, dá-se mais atenção a noesis e não à semiose.

A segunda hipótese, a compreensão (integral) de um conteúdo conceitual, repousa sobre a coordenação de ao menos dois registros de representação, e essa coordenação manifesta-se pela rapidez e espontaneidade da atividade cognitiva de conversão. Essa hipótese apela para outra descrição da estrutura de representações semióticas e de seu funcionamento. Para ilustrar essa situação, vejamos a figura 1:

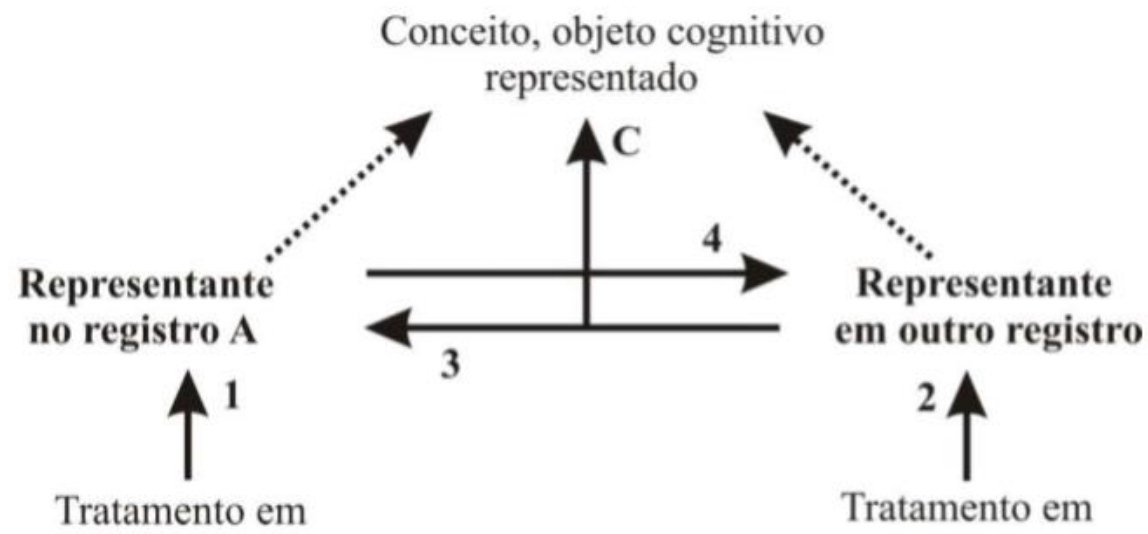

Figura 1 - Hipótese fundamental de aprendizagem: estrutura da representação em função de conceitualização. Fonte: Duval (2012, p. 282).

Logo, podemos examinar que as flechas 1 e 2 correspondem às transformações internas a um registro. As flechas 3 e 4 às transformações externas, ou seja, houve uma mudança de registro por conversão. Observamos que as flechas 1 e 2 convergem para a flecha $C$, em outras palavras, essa última vai corresponder à compreensão integral de uma 
representação, pois supõe uma coordenação de dois registros. E por fim, as flechas pontilhadas que marcam a distinção clássica entre representante e representado.

Ressaltamos que o esquema apresentado na figura 1 é o mais simples de coordenação de dois registros. E que, dependendo do objeto matemático a ser tratado, pelo menos uma coordenação entre três registros poderá ser requisitada. Para Duval (2012, p. 282, grifo nosso), da mesma forma "é possível ver uma das possibilidades importantes da estrutura da representação: o representante de um registro pode ser considerado como o representante de outro registro, como é o caso em uma relação entre texto e imagem".

Na maioria dos alunos, há um isolamento de registros de representação. Eles não reconhecem o mesmo objeto nas representações que são dadas em sistemas semióticos diferentes. Por exemplo, a expressão numérica de uma relação e sua representação geométrica sobre uma reta ou no plano. E afirma Duval (2012), que esse isolamento subsiste, mesmo após um ensino de conteúdos matemáticos que tenha tido esses diferentes registros amplamente utilizados. E ainda complementa quando afirma que esta compreensão monoregistro conduz a um trabalho às cegas, sem possibilidade de controle do "sentido" daquilo que é feito.

Destarte Duval sugere, em sua Teoria dos Registros de Representação Semiótica, uma aprendizagem que considere a ligação estreita que existe entre a noesis e semiose. Para tanto, deve-se elevar os alunos a uma condição de tomada de conscientização mais global e, para tal, são necessárias atividades de ensino mais específicas.

Nesse viés, ele descreve três tipos de atividades extremamente diferentes: a primeira concerne à apreensão das representações semióticas; a segunda à aprendizagem de tratamentos próprios de uma certa categoria de registros; e a terceira ao modo de produção de representações complexas.

Conforme Duval (2012), pode-se dizer, que nessas condições, as atividades de construção "ensinam a ver", isto é, permitem descobrir, mobilizar e controlar a produtividade heurística das figuras.

Os tratamentos que constituem a produtividade heurística das figuras geométricas combinam operações que não se mostram ser nem do tipo de apreensão puramente perceptiva, nem do tipo conceitual. Em certos casos, os fatores próprios à apreensão perceptiva podem favorecer estas operações e, em outros casos, ao contrário, inibi-las. Além disso, estas operações são independentes de todo raciocínio dedutivo e do emprego de definições (DUVAL, 2012, p. 287).

Partimos então para distinguir a apreensão operatória das figuras da apreensão perceptiva, da apreensão discursiva e sequencial, como coloca Duval (1994 apud FACCO, 2003, p.35):

Operatória: apreensão sobre as modificações possíveis de uma figura de partida e as reorganizações perceptivas que essas modificações sugerem; Perceptiva: interpretação das formas da figura em uma situação geométrica;

Discursiva: compreensão dos elementos da figura geométrica, por meio da articulação dos enunciados relacionados às propriedades do objeto, e Sequencial: possível nas tarefas de construção ou de descrição com o objetivo de reproduzir uma figura. 
Uma aprendizagem dos tratamentos propriamente figurais deve ser uma aprendizagem centrada na apreensão operatória das figuras e não nas apreensões sequenciais e discursivas. Deve-se ponderar sobre todos os fatores que mexem com a visibilidade de uma operação, ou seja, os fatores de organização perceptiva de uma figura que podem contribuir para a mobilização espontânea dessa operação ou, ao contrário, inibi-la.

Para Duval (2012) são radicalmente diferentes: as conversões e os tratamentos. Enfim, permite ainda compreender por que o entendimento dos objetos e dos conceitos em matemática começa, somente, no momento em que o aluno é capaz de mobilizar e de coordenar espontaneamente dois registros de representação para um mesmo objeto. Obtêm-se, assim, as bases de um modelo cognitivo de funcionamento do pensamento que atende todos os problemas suscitados no ensino de matemática.

Por conseguinte, D'Amore (2015, p. 165), afirma que "Um conceito é considerado construído quando o estudante tem condições de identificar as propriedades do conceito, de representá-lo, de transformar tal representação, de utilizá-lo de maneira adequada".

Portanto, baseando-se na Teoria das Representações Semióticas proposta por Duval, é possível verificar indícios de aprendizagem através das representações fornecidas pelos alunos.

Para corroborar com a análise semiótica dos registros de representação, buscamos analisar conjuntamente tais representações a práticas pesqueiras da cultura local, fundamentando-nos na Etnomatemática e, mais especificamente, na ideia de Etnocomunidade. Isso foi possível devido aos princípios e elementos teóricos desse campo coadunarem com a pesca artesanal praticada pela população da região de Vigia de Nazaré. Esse contexto permite de maneira didática a articulação entre os ideais teóricos do Registro de Representação e da Etnomatemática, uma vez que a representação, as conversões e tratamentos terão impacto diretos nas tarefas propostas no contexto da prática pesqueira.

De acordo com D'Ambrosio, "a Etnomatemática é uma matemática praticada por grupos culturais, tais como comunidades urbanas ou rurais, grupos de trabalhadores, classes profissionais, sociedades indígenas e outros tantos grupos que se identificam por objetivos e tradições comuns" (D'AMBROSIO, 2001, p.9). Ao abordarmos a etnocomunidade, evidenciamos que uma prática pode ser compartilhada ou desenvolvida por um grupo de pessoas que mobilizam outras de interesse comum.

\section{Notas metodológicas}

Caracterizamos nossa pesquisa como sendo exploratória, de abordagem qualitativa e de tipo etnográfica, pois de acordo com Gil (2008, p. 27),

Muitas vezes, as pesquisas exploratórias constituem a primeira etapa de uma investigação mais ampla. Quando o tema escolhido é bastante genérico, tornam-se necessários seu esclarecimento e delimitação, o que exige revisão da literatura, discussão com especialistas e outros procedimentos. O produto final deste processo passa a ser um problema mais esclarecido, passível de investigação mediante procedimentos mais sistematizados. 
No que tange a sua abordagem, a pesquisa qualitativa preocupa-se com aspectos da realidade que não podem ser quantificados, centrando-se na compreensão e explicação da dinâmica das relações sociais. Segundo D’Ambrósio (1996, p.103), esse tipo de pesquisa é focalizado no indivíduo com toda sua complexidade, na sua inserção e interação com o ambiente sociocultural e natural. Em relação ao tipo de pesquisa, para Severino (2007, p. 119), a do tipo etnográfica visa compreender, na sua cotidianidade, os processos do dia a dia em suas diversas modalidades, haja vista se tratar de um mergulho no microssocial, olhado com uma lente de aumento e aplicados métodos e técnicas compatíveis com a abordagem qualitativa.

Assim, no primeiro momento realizamos uma pesquisa de campo com 100 alunos de uma Escola Estadual de Ensino Médio localizada no município de Vigia de Nazaré com o intuito de levantar possíveis temas de estudos que fossem relevantes para a localidade na visão dos alunos. Os resultados obtidos junto a eles foram decisivos para a definição da pesca como tema desta pesquisa.

Dessa forma, os sujeitos de nossa pesquisa foram onze alunos egressos do nono ano do Ensino Fundamental de uma Escola pública localizada na zona urbana de Vigia de Nazaré no estado do Pará. Esses alunos são representados em nossa pesquisa por A1, A2, A3, A4, A5, A6, A7, A8, A9, A10, A11. Durante a realização das atividades, eles agruparam-se em duplas fixas, e por isso foi possível formar cinco duplas, e uma das alunas preferiu realizar a atividade individualmente, no decorrer da intervenção.

As tarefas aqui apresentadas são recortes de um projeto que buscou mapear as principais atividades econômicas da referida região, assim como quais seriam do interesse dos alunos abordarem nas aulas de matemática. Destarte, tomamos como contexto para o ensino de noções matemáticas a pesca artesanal e então, elaboramos uma sequência de 13 tarefas, das quais apresentamos aqui um recorte daquelas cinco relacionadas com a noção de raciocínio proporcional (LEÓN; MAYORGA; SÁNCHEZ, 2007).

\section{Resultados e discussão}

Iniciamos a discussão com um texto (de autoria própria) que serviu de ponto de partida para os estudos subsequentes cujo título era A rede no contexto da pesca artesanal em Vigia de Nazaré - PA. O objetivo era descobrir relações de proporcionalidade concernentes à confecção e utilização das redes de pesca artesanal.

Texto

A rede de pesca é essencial para a atividade artesanal. Uma cena muito comum do município de Vigia de Nazaré é encontrar pessoas tecendo ou consertando redes de pesca na orla da cidade ou em frente às suas residências, confirmando a influência da atividade pesqueira na economia local.
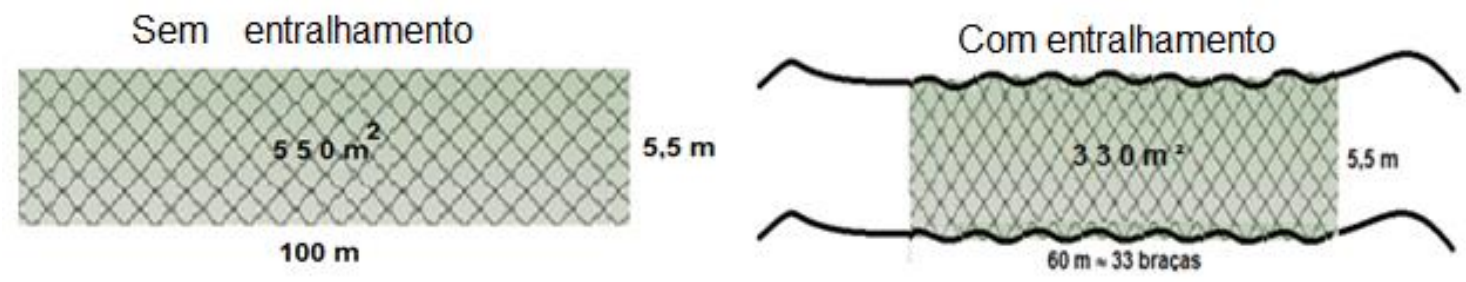

Figura 2 - Panagem de rede, sem e com o entalhamento. Fonte: Os autores (2018). 
No contexto da pesca exercida na região, costuma-se chamar de panagem de rede um trecho retangular com 100 metros de comprimento por aproximadamente 5,5 m de largura. Com essas dimensões, cada panagem pode cobrir uma área submersa de aproximadamente $550 \mathrm{~m}^{2}$. Após o entralhamento, cada panagem de rede tem seu comprimento reduzido para aproximadamente 60 metros ou 33 braças (Figura 2).

O entralhamento da rede consiste em costurar as panagens de rede sistematicamente a um cabo superior e a um inferior utilizando-se encalas, que são presilhas igualmente espaçadas (ver imagens 3 e 4), e permitem que se crie na rede uma espécie de "saco" no momento em que ela é puxada pela embarcação. Assim, a rede precisa ser entralhada antes de "ir ao mar", pois do contrário, com a rede tesa, o peixe bate e volta dificultando sua captura.

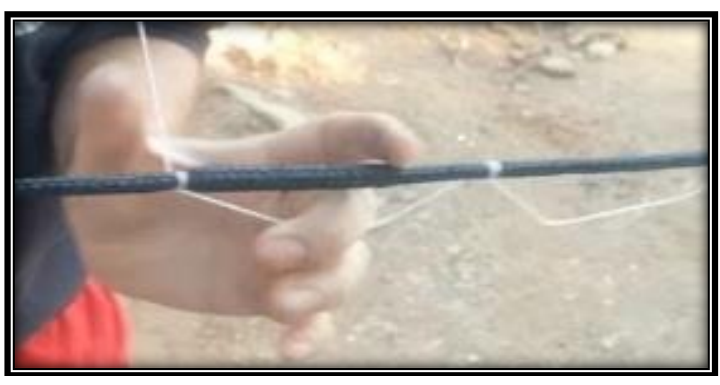

Figura 3 - Tecendo as encalas, igualmente espaçadas. Fonte: Os autores (2018).

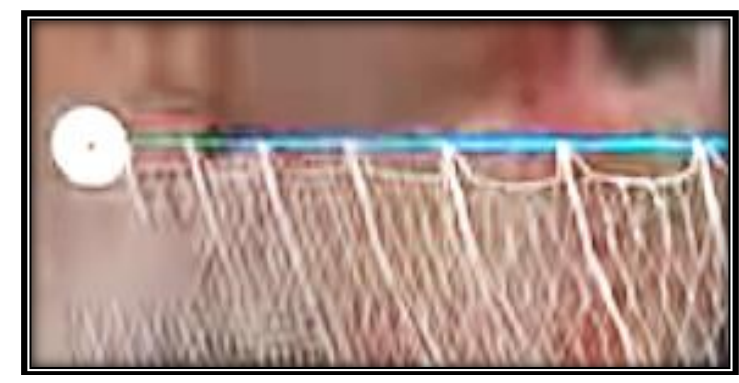

Figura 4 - Detalhe das encalas na rede já entralhada. Fonte: Os autores (2018).

Para confeccionar redes, é possível comprar panagens prontas e costurá-las umas às outras até o comprimento de rede desejado. Outra opção consiste em comprar separadamente o material necessário e tecê-las desde o início.

A unidade utilizada pelos pescadores para medir o comprimento das redes é a braça. Ela equivale à distância entre as duas mãos com os braços totalmente abertos. Por usar partes do corpo humano, o tamanho da braça é variável, diminuindo sua precisão, proporcionando por outro lado, maior agilidade na medição das redes. Segundo os pescadores, depois de entralhada, uma panagem de rede equivale a aproximadamente 33 braças (60 $\mathrm{m} \cong 33$ braças).

As redes de pesca são constituídas de malhas, cujas medidas variam de acordo com a espécie de peixe que se pretende capturar. Para padronizar as malhas da rede, os artesãos geralmente utilizam um pequeno pedaço de madeira retangular, conhecida entre eles como bitola. Como exemplo, uma bitola $9 \mathrm{~cm}$ de comprimento é utilizada para confeccionar redes de malha $18 \mathrm{~cm}$ ou $180 \mathrm{~mm}$ para pescar espécies maiores de peixes como Pescada Amarela e a Gurijuba (Figura 5).

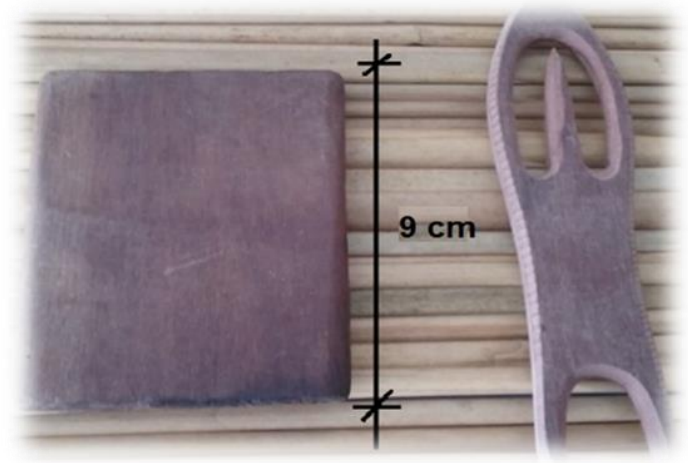

Figura 5 - Bitola $9 \mathrm{~cm}$ e agulha para tecer rede. Fonte: Os autores (2018). 
O tamanho da malha utilizada define o tamanho do peixe a ser capturado. O quadro 1 mostra algumas espécies de peixes e a largura da malha em milímetros apropriada para a captura dessas espécies.

Quadro 11 - Quadro de malhas de rede de pesca

\begin{tabular}{c|c}
\hline Espécie de Peixes & Largura da malha $(\mathrm{mm})$ \\
\hline Sardinha & 30 a 43 \\
\hline Sarda pequena & 50 \\
\hline Sarda grande & 80 \\
\hline Corvina & 140 a 160 \\
\hline Dourada & 130 a 160 \\
\hline Pescada Amarela & 180 a 200 \\
\hline
\end{tabular}

Fonte: Os autores (2018).

A partir da leitura e discussões do texto passamos a resolver as tarefas propostas.

\section{Questão 1}

Na primeira questão, o aluno deveria estabelecer uma relação entre os comprimentos das panagens de rede entralhada e não entralhada, caracterizando uma transformação por conversão, passando do registro da língua natural para o registro simbólico, utilizando a representação algébrica. Ademais, pedia-se a representação da rede entralhada e da rede não entralhada por meio de um desenho com o objetivo de articular o contexto sociocultural e didático no ensino de matemática. Assim, buscamos um diálogo entre a perspectiva da Etnomatemática na abordagem da Etnocomunidade com a concepção teórica do Registro de Representação Semiótica.

Ao analisarmos os registros escritos relativos à primeira questão fornecidos pelos alunos, observamos que todos eles reproduziram a rede de pesca ilustrada no texto, retirando corretamente os valores necessários para solucionar a questão e comentando em linguagem natural as informações relevantes sobre a relação solicitada, indicando boa compreensão do texto. No entanto, nenhum aluno realizou a conversão do registro da língua natural para o registro simbólico, por meio da representação algébrica, para determinar a proporção existente entre as redes entralhada e não entralhada.

Em destaque, o registro escrito do aluno A11 (Figura 6) mostra que esse identifica a diminuição de 40 m resultantes do processo de entralhe da rede por meio da língua natural.

A pamagem main intralhada

tom soo metrios de compruminto

por S,S de lonquira, tá a que

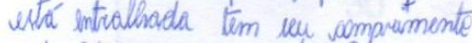

vedunido para co mentio. On uja

a. panagiam quando í entrolhoda

dimimui 40 metror dollompruminto

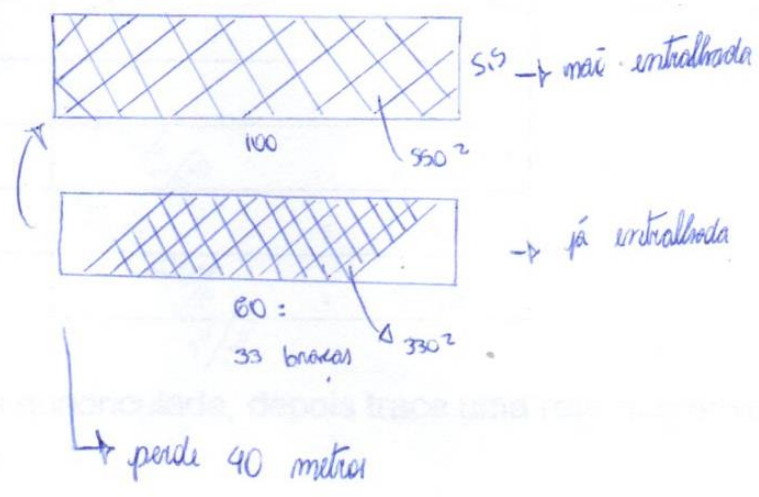

Figura 6 - Registro do aluno A11. Fonte: Dados da pesquisa (2018). 
O aluno A3 (Figura 7) destaca, além da diminuição de 40 metros da rede, a criação de uma espécie de saco após o processo de entralhe da rede, necessário para a captura do pescado, indicando que o contexto envolvendo a prática social dessa Etnocomunidade auxilia na compreensão do que trata a tarefa.

\section{Quande entralerada Rara pader Regar as plixees. \\ a rede}
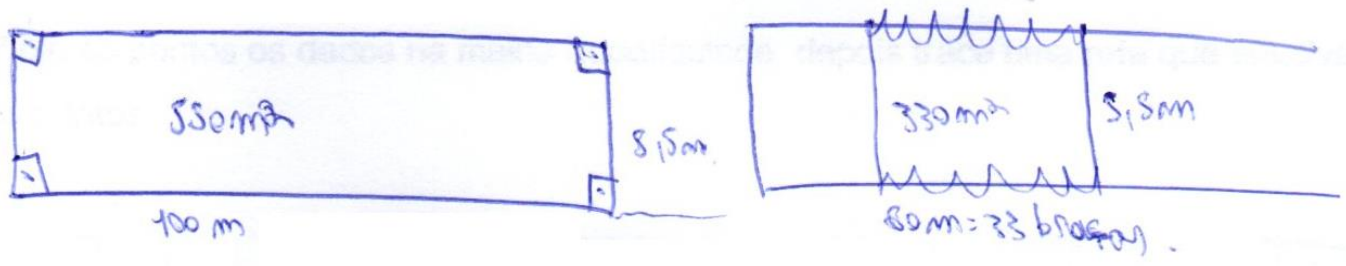

Figura 7 - Registro referente ao aluno A3. Fonte: Dados da pesquisa (2018).

Ademais, o registro semiótico da aluna A9 (Figura 8) mostra que além de perceber a redução da rede em 40 metros, relaciona tal situação com a formação do "saco" essencial para a captura do pescado. Observamos que A9 busca representar a captura dos peixes em sua representação gráfica indicando que a situação próxima de sua realidade é um instrumento de auxílio na resolução. E ainda permite concluir que a vinculação de situações culturais ao processo educativo favorece o engajamento do aluno na realização da tarefa e na justificativa do resultado.

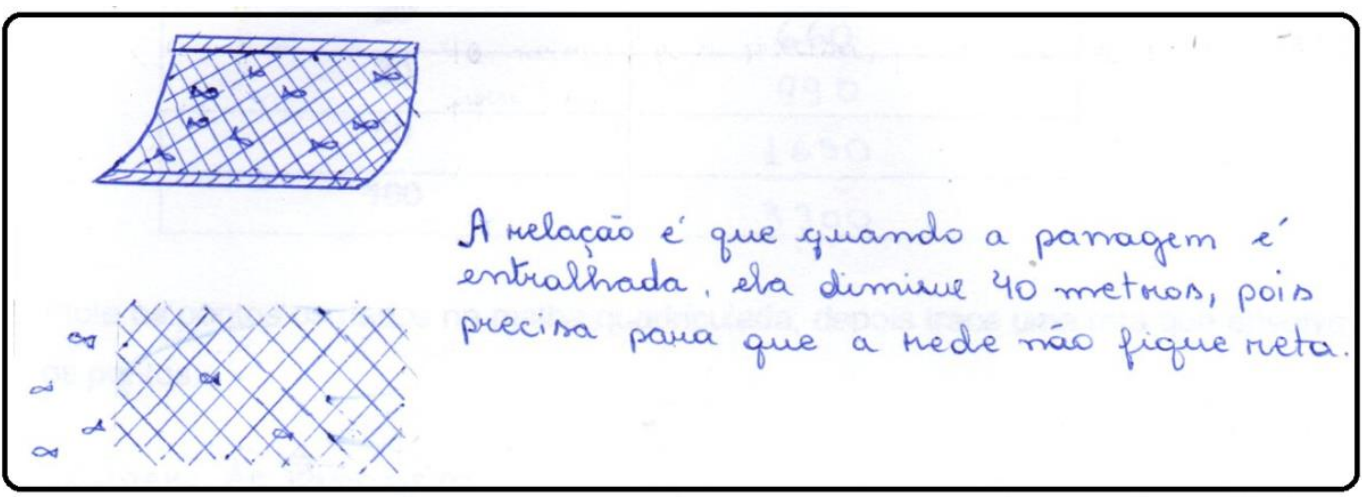

Figura 8 - Registro fornecido pelo aluno A9. Fonte: Dados da pesquisa (2018).

Portanto, além da representação algébrica relacionada à proporção, considera que a panagem entralhada equivale a 0,6 ou 60\% da panagem não entralhada e dessa forma, há no processo de entralhe, uma perda média de $40 \%$ no seu comprimento.

Diante disso, de maneira geral, verificamos que os alunos apresentaram nessa primeira questão, um problema de conversão, não conseguindo expressar em linguagem algébrica as informações gráficas da primeira questão. Mas evidenciamos que o contexto envolvendo 
as práticas culturais locais da pesca apresenta-se como elemento motivador e facilitador de compreensões dos objetos matemáticos envolvidos na tarefa.

Na segunda questão, o aluno deveria determinar o comprimento em braças de uma rede de pesca, a partir das informações sobre panagens de rede expressas no texto. A maioria dos alunos realizou a conversão mudando do registro da língua natural para o registro simbólico, através das representações numéricas ou utilizando o registro em língua natural. O registro semiótico do aluno A11 (Figura 9) exemplifica o procedimento utilizado pela maioria dos alunos para encontrar a resposta da questão e o registro escrito do aluno A5 (Figura 10) mostra o uso da língua natural na resolução.

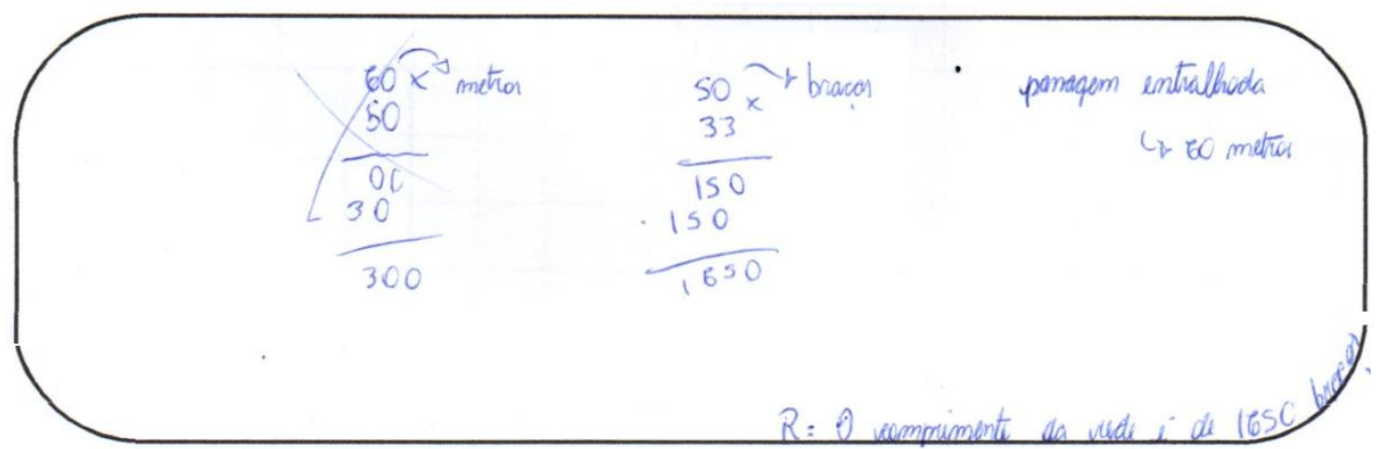

Figura 9 - Registro do aluno A 11 sobre representação numérica. Fonte: Dados da pesquisa (2018).

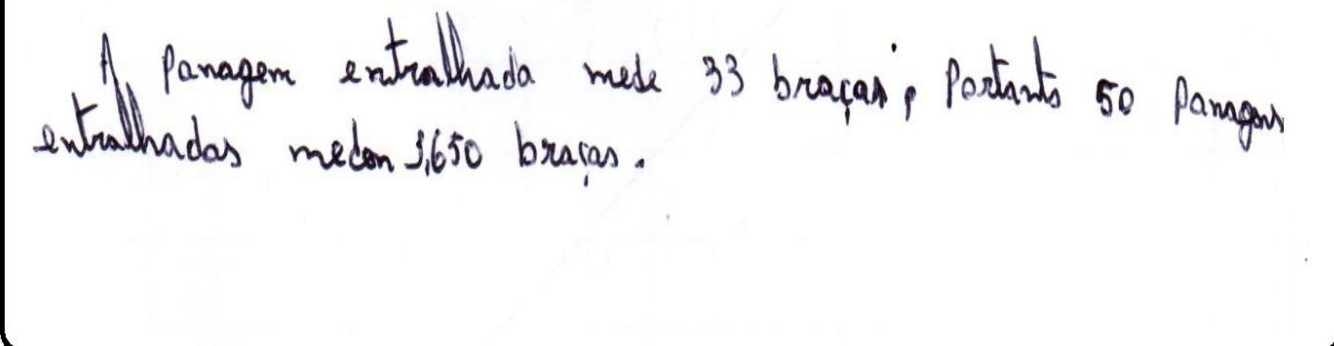

Figura 10 - Registro do aluno A5 sobre representação numérica. Fonte: Dados da pesquisa (2018).

Ressaltamos que o aluno A4 (Figura 11), além de determinar o comprimento da rede em braças como era solicitado, encontrou também o comprimento da rede em metros, indicando que articula adequadamente os recursos matemáticos necessários para resolver uma proporção. O registro escrito fornecido mostra duas setas no interior de um retângulo utilizado para representar uma panagem de rede, apontando o procedimento utilizado para calcular a área a ser coberta por essa panagem, mostrando conhecer o cálculo de áreas de figuras planas.

Uma das duplas, formada pelos alunos A9 e A10, realizou a conversão mudando do registro da língua natural para o registro simbólico por meio das representações algébricas, utilizando a regra de três. Tomando como exemplo o registro do aluno A10 (Figura 12), observamos que o aluno mobilizou conhecimentos prévios já presentes em sua estrutura cognitiva para resolver a questão proposta e realizou a transformação por conversão. 

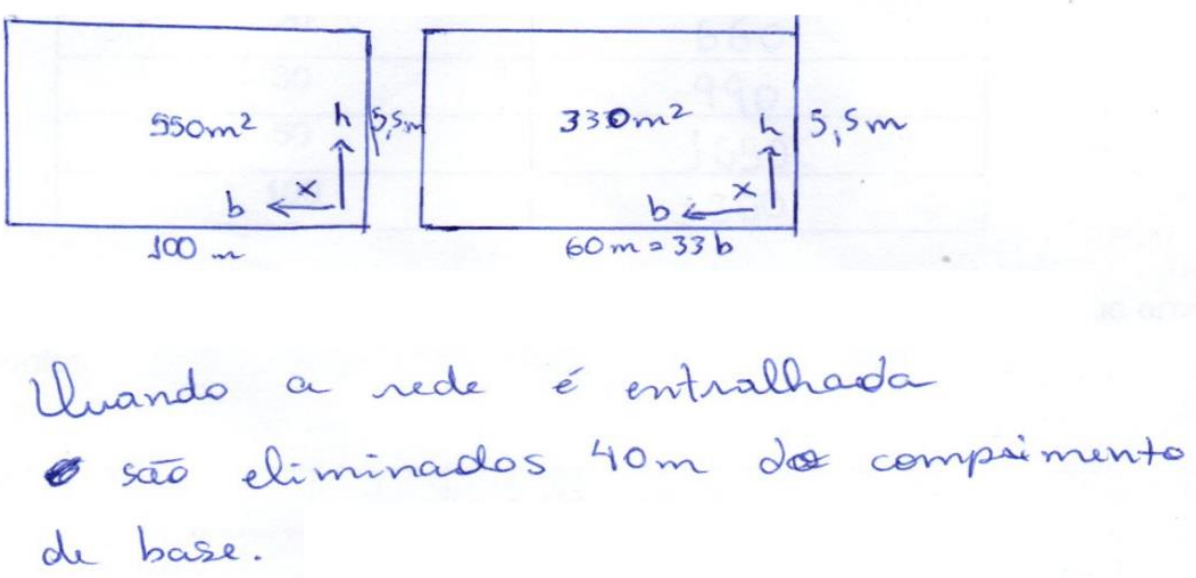

Figura 11 - Registro do aluno A4. Fonte: Dados da pesquisa (2018).

Apesar de a maioria dos alunos não utilizarem a representação algébrica, todos responderam corretamente o valor esperado para a questão. Ademais, os diferentes procedimentos utilizados nas resoluções valorizaram o momento de socialização entre as equipes, revelando aos alunos a variedade de estratégias de resolução para se chegar à resposta correta da referida questão. A relação entre os saberes da Etnocomunidade e escolares revela como um saber apresenta-se funcional na perspectiva de reunir aspectos da vivência comunitária e da educação ambiental, uma vez que favorecem o engajamento em torno de um objetivo comum que são os aspectos educativos envolvendo práticas da profissão. Tal articulação revela que os saberes matemáticos manipulados por esses alunos vão adiante das manifestações essencialmente prático-utilitárias, próprias do âmbito da vida cotidiana discutidos por Giardinetto (1999).

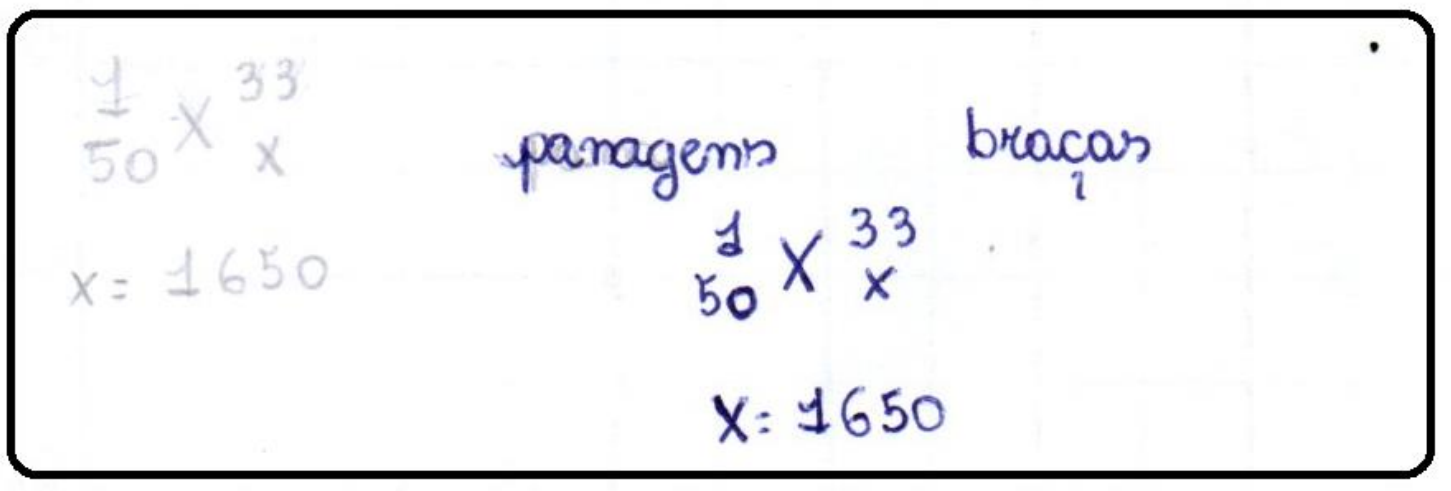

Figura 12 - Registro do aluno A10. Fonte: Dados da pesquisa (2018).

$\mathrm{Na}$ terceira questão, o aluno deveria preencher uma tabela concernente ao comprimento de uma rede de pesca, estabelecendo uma relação entre o número de panagens da rede e o número de braças de seu comprimento.

Nesse sentido, o preenchimento da tabela caracteriza uma transformação por conversão, mudando o registro em língua natural para o simbólico através de uma representação tabular. A transformação por conversão (mudança do registro na língua natural para o registro simbólico) necessária para o preenchimento da tabela estava relacionada ao cálculo de proporções abordado na questão anterior, facilitando a compreensão da conversão fundamental para resolver essa questão. 
Em seguida, O registro escrito do aluno A5 (Figura 13) evidencia o cálculo dos valores por meio da proporção. Outrossim, o registro escrito do aluno A2 (Figura 14) aponta o cálculo dos valores utilizando a multiplicação direta. Esses registros representam os dois procedimentos distintos utilizados pelos os alunos para calcular o número de braças e preencher a tabela referente à primeira transformação por conversão.

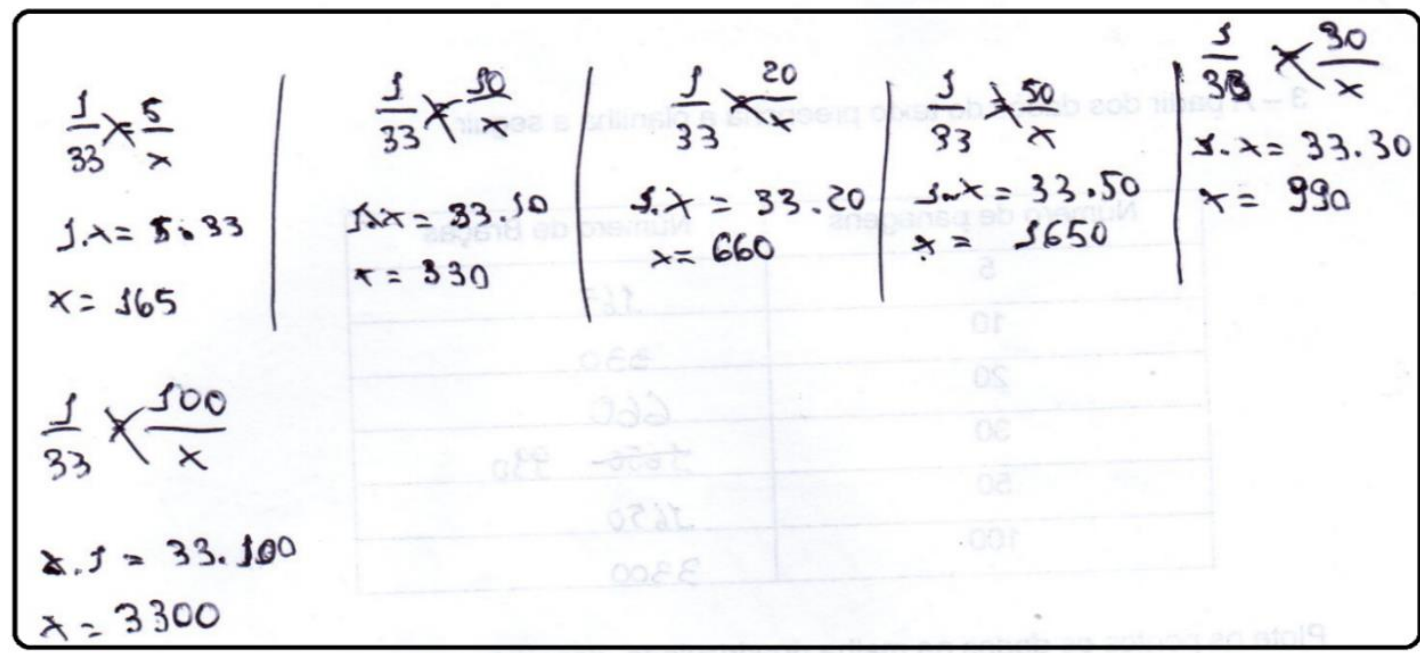

Figura 13 - Registro do aluno A5 utilizando a proporção. Fonte: Dados da pesquisa (2018).

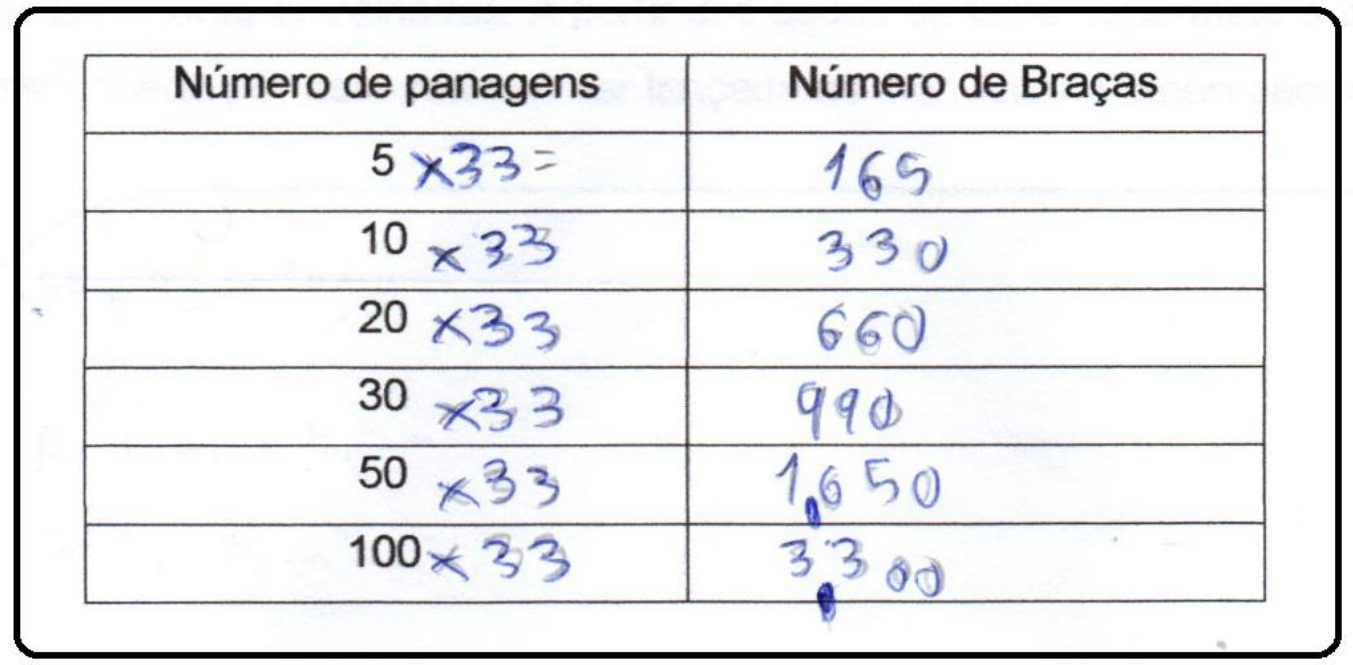

Figura 14 - Registro do aluno A2 utilizando a multiplicação direta. Fonte: Dados da pesquisa (2018).

As análises dos registros escritos dos alunos mostraram que a conversão referente à representação tabular foi realizada corretamente por todos os alunos, utilizando-se preferencialmente a proporção para encontrar os valores da tabela.

Isto posto, as práticas construídas sobre princípios que contemplem e mobilizem atividades escolares com atividades extraescolares $\overline{\bar{T}}_{\bar{T}}$ parecem expressivas para as Etnocomunidades das zonas pesqueiras $\bar{T}_{T}$ que utilizam práticas com matemáticas. Isso decorre, principalmente, por conseguirem harmonizar atividades laborais e estudo em jogo. Entendemos que a busca por novas abordagens de ensino nas práticas escolares, em qualquer área de conhecimento e contexto, que respondam mediante o ensino significativo para os sujeitos envolvidos, constituem-se como grande desafio para o processo educacional da escola pública brasileira, sobretudo nas comunidades específicas, como nas 
zonas rurais, ribeirinhas etc. Nesses termos, a Etnomatemática, no sentido da Etnocomunidade é fecunda para articulações de campos teóricos diversos agregando-os.

Na quarta questão, o aluno deveria estabelecer uma relação proporcional entre a área coberta por uma panagem de rede entralhada e uma rede composta por cinquenta dessas panagens através da proporção ou da regra de três, caracterizando uma transformação por conversão, passando do registro da língua natural para o registro simbólico, utilizando a representação algébrica. Para instigar a resolução da questão na forma esperada, perguntava-se qual a proporção existente na referida questão.

Essa quarta questão está relacionada com o cálculo de proporção envolvendo a área submersa de uma rede de pesca e é similar à segunda questão desta atividade sobre o comprimento de rede. A análise dos registros escritos fornecidos pelos alunos mostra a utilização da multiplicação direta como a principal estratégia de resolução, substituindo a representação algébrica pela proporção ou regra de três. No entanto, a transformação por conversão realizada pelos alunos foi incrementada com representações gráficas que auxiliaram nos cálculos utilizados para responder corretamente à questão, caracterizando uma conversão para o registro figural.

Os registros escritos dos alunos A10 (Figura 15) e A4 (Figura 16) apresentam, respectivamente, a utilização da multiplicação direta como estratégia de resolução e o registro da língua natural para expressar a proporção existente na quarta questão, ambos auxiliados por uma representação gráfica da rede.

Todos os alunos encontraram a resposta esperada para essa questão, realizando uma transformação por conversão e, apesar de não utilizarem a representação algébrica, chegaram à resposta utilizando operações matemáticas mais simples e representando graficamente a rede para auxiliar na resolução, mobilizando registros diferentes e indicando que conseguem extrair corretamente informações de um texto para solucionar problemas.

O conflito entre os contextos matemáticos e extramatemáticos com jeitos de pensar e fazer distintos parece ser minimizado mediante a imbricação dos referidos contextos. No entanto, a complexidade de compreensão das realidades em jogo pode ser um entrave para abordagens que interconecte a realidade laboral local e o ensino da matemática. Como podemos notar, a noção de proporção não está unicamente determinada por uma forma de fazer, pois a diversidade de possíveis técnicas de resolução decorre de seus usos em diferentes atividades da Etnocomunidade.

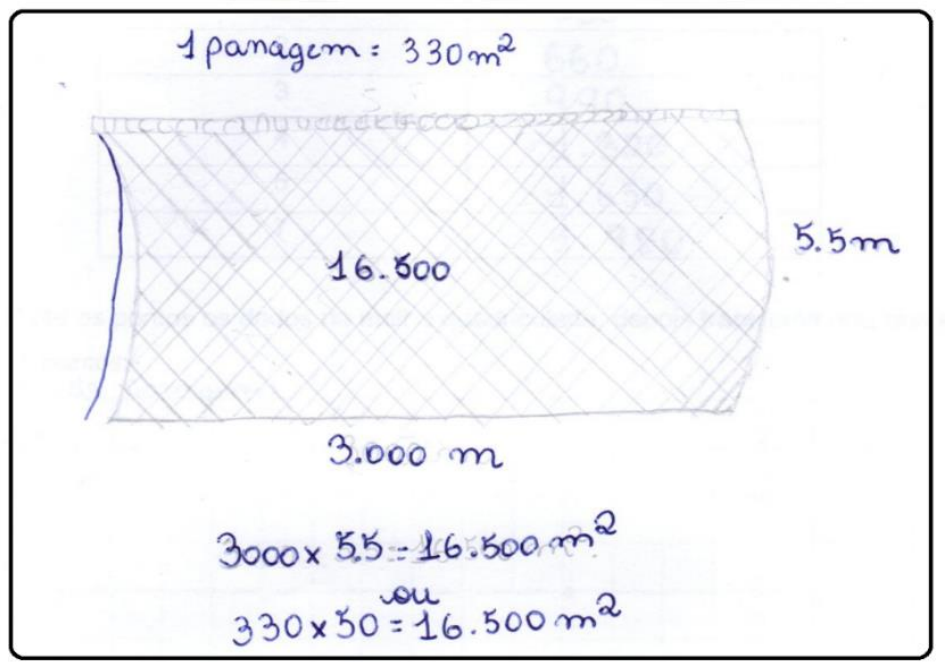

Figura 15 - Registro do aluno A10 referente a conversão. Fonte: Pesquisa (2018). 


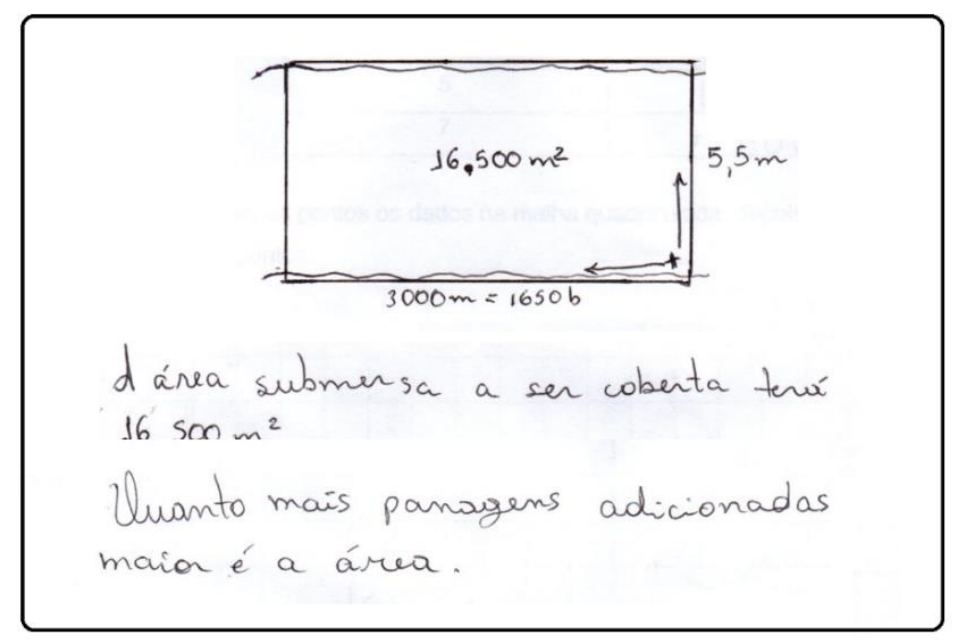

Figura 16 - Registro do aluno A4 referente à conversão. Fonte: Pesquisa (2018).

Na quinta questão, o aluno deveria preencher uma tabela com o número de malhas existentes em uma rede de pesca, de acordo com o seu comprimento dado em número de panagens. A partir dos dados obtidos com o preenchimento da tabela, o aluno deveria marcar os pontos no eixo cartesiano em uma malha quadriculada.

Dessa forma, o preenchimento da tabela caracteriza uma transformação por conversão, mudando o registro em língua natural para o registro simbólico por meio de uma representação tabular. Por outro lado, marcar os pontos na malha caracteriza uma nova transformação por conversão, mudando dessa vez, o registro simbólico expresso na representação tabular para o registro figural por meio de uma representação gráfica.

Constatamos que o procedimento de resolução foi compreendido pelos alunos, pois realizaram a primeira transformação por conversão e preencheram corretamente a tabela com o número de malhas existentes em uma rede. Assim, os alunos conseguiram preencher e representar graficamente os dados encontrados na tabela, caracterizando a realização das duas transformações por conversão solicitadas na questão.

Os registros escritos dos alunos A9 (Figura 17) mostram os diferentes cálculos utilizados e as representações gráficas aplicadas no registro figural desse aluno.

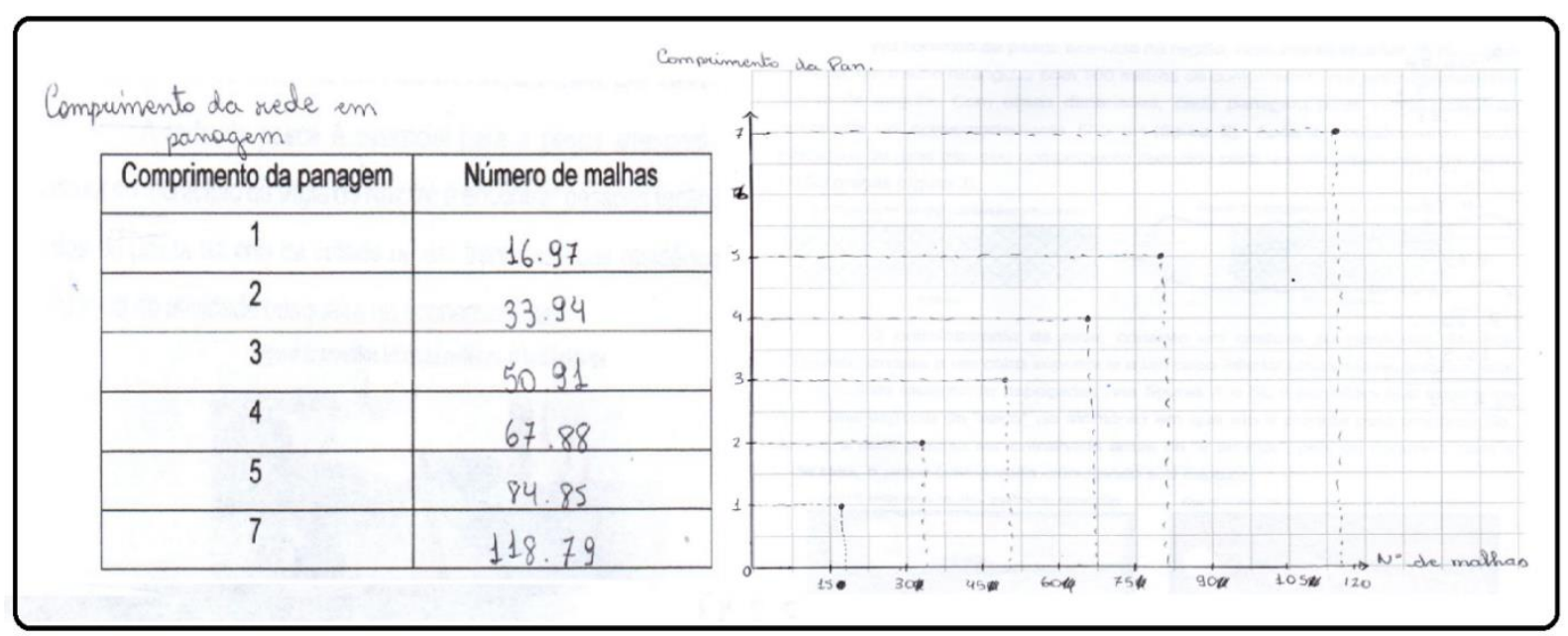

Figura 17 - Registro do aluno A9 referente as duas conversões realizadas. Fonte: Pesquisa (2018). 
Ao analisar especificamente os registros escritos do aluno A5, constatamos a evolução de suas representações gráficas ao longo das atividades. A5 utiliza a multiplicação direta para encontrar corretamente o número de malhas e plota corretamente os pontos, empregando uma escala adequada.

Não está em jogo estritamente o conhecimento matemático, mas seu uso nas práticas específicas das atividades de pesca. As práticas com matemáticas da Etnocomunidade envolvem relações sociais da pesca, turismo, comércio em geral etc., mas prevalecem e se acentuam na atividade pesqueira; , fazendo com que os objetos matemáticos, a exemplo da noção de proporção articulada a outros saberes, como no caso aqui tratado, área de figuras planas e raciocínio funcional, ganhem status de uma ferramenta significada na prática, e no ensino de matemática. Nessa perspectiva, podemos fazer uso desse e de outros contextos para atender predominantemente uma prática social de um grupo específico.

As atividades apresentadas são supostamente do tipo vivenciadas implicitamente pelo aluno em suas práticas ou de seus familiares, uma vez que os assuntos tratados nas resoluções são encontrados em livros didáticos e ensinados pelos professores nas escolas locais. A questão é que nem sempre ou raramente os agentes da escola ouvem a comunidade para ensinar a partir das práticas das realidades locais. Nessa perspectiva, a resolução do aluno extrapola as operações matemáticas básicas, pois está em jogo a análise do contexto que permite vislumbrar a situação de forma integrada. O aluno encontra à solução da atividade proposta usando as práticas operacionais rotineiras da escola, porém com uma leitura e compreensão que emanam uma razão de ser e de se estudar os assuntos tratados. Os alunos agregam aos estudos dos objetos matemáticos condições para o convívio entre suas práticas e/ou de seus familiares a situações em contextos que são vitais para suas atividades pesqueiras.

De maneira geral, ao final das atividades, constatamos que os alunos conseguiram mobilizar pelo menos dois registros de representação semiótica para os conceitos matemáticos abordados durante a resolução das questões, à vista disso, segundo Duval (2009), temos indícios que houve aprendizagem. Por outro lado, percebemos o interesse e satisfação dos alunos em aprender conteúdos matemáticos a partir de elementos ligados à pesca artesanal típicos do município. À medida que as atividades eram desenvolvidas, verificamos que a turma se envolvia nas discussões e resoluções estabelecendo um ambiente de aprendizagem favorável à apreensão dos conhecimentos em jogo relacionados aos saberes matemáticos e da prática da pesca.

\section{Considerações finais}

Entendemos que a articulação de saberes presentes nas atividades, que envolve de certo modo a qualificação profissional referente ao trabalho de pesca artesanal, circunscreve entre outras, as ações de cidadania e de acesso dos educandos aos saberes instituídos na escola além da providência de uma formação integral ajustada ao contexto sócio-político local. Esse ambiente foi vislumbrado em decorrência de suas peculiaridades na atividade de pesca que necessitam de conhecimentos de objetos da escola, em particular no ensino de matemática.

As lentes teóricas da Etnomatemática e da TRRS permitiram observar o contexto da pesca artesanal imersa numa Etnocomunidade em que o raciocínio proporcional se articula com vários outros saberes, mesmo que os sujeitos não se deem conta disso, e por sua 
funcionalidade nesse contexto, oportunizou-nos refletir sobre elementos significantes do contexto mencionado, subjacentes, facilitadores ou perturbadores, das práticas de pesca. Outrossim, as atividades da pesca não são produtos exclusivos de tarefas artificiais sobre contextos de semirrealidades criados pela escola, mas essencialmente das práticas sociais que vivem na Etnocomunidade.

A Educação Matemática, como campo teórico de investigação, não pode ignorar as problemáticas relativas ao saber matemático, aqui evidenciadas através dos aportes teóricos da TRRS e da Etnomatemática, tendo em conta que as práticas socioculturais, como o raciocínio proporcional que vivem nas práticas rotineiras dos sujeitos, devam desconsiderar ou substituir, ou descaracterizar uma prática de cultura matemática como adequada ou inadequada, como inferior ou superior, como dominante ou dominadora, pois, cada uma possui sua infraestrutura matemática mais simples ou complexa, mais sofisticada ou menos sofisticada que tem sua utilidade prática social e também ideológica.

Assim, foi possível contextualizar noções do raciocínio proporcional articuladas a outros saberes às práticas laborais da pesca a partir da conjunção de ideias da Etnomatemática, no sentido da Etnocomunidade, e da Teoria dos Registros de Representação Semiótica. Nesse contexto, com aspectos teóricos utilizados para analisar as nuances do contexto da pesquisa e do objeto de estudo, esperamos ter contribuído para evidenciar possíveis articulações de teorias, que muitas vezes são consideradas apartadas conceitualmente por seus fundamentos filosóficos.

Ao realizarmos o experimento didático, observamos que as atividades possibilitaram o desenvolvimento de importantes habilidades cognitivas nos alunos, como desenvolvimento da leitura e interpretação de textos, foco, persistência, autonomia, raciocínio lógico matemático e capacidade de construir figuras, bem como a visualização oriunda dessa representação embasada na prática dos sujeitos deu apoio as resoluções dos problemas. As discussões realizadas em sala de aula, com os alunos apresentando suas soluções, contribuíram para o desenvolvimento dessas habilidades e caracterizaram a etapa de socialização como um momento de grande importância na aprendizagem dos alunos.

Apesar das dificuldades iniciais provenientes da utilização de uma nova abordagem na sala de aula de matemática, observamos que os alunos se adaptaram rapidamente à proposta metodológica e se mostraram muito interessados em realizar as tarefas por meio do trabalho colaborativo, ratificando um impacto positivo da sequência de atividades proposta. Ressaltamos que à medida que as atividades eram resolvidas, o tempo de execução diminuía sensivelmente.

Com isso, a realização da sequência permitiu gerar em sala de aula um ambiente favorável para o desenvolvimento da aprendizagem. Verificamos que aqueles alunos que se mostraram pouco participativos no início da intervenção, foram desenvolvendo uma postura mais ativa durante a realização das atividades, passando a escrever respostas no quadro e verbalizando suas opiniões para o grupo quando era necessário. Ademais, a sequência desenvolvida estimulou o espírito investigativo dos alunos, pois observamos que eles passaram a procurar saber mais sobre aspectos da pesca artesanal praticada na cidade, como a confecção e utilização das redes de pesca, desenvolvendo sua percepção em relação ao meio em que vivem.

Durante a resolução das atividades procurávamos sempre estimular o raciocínio lógico matemático dos alunos, incentivar a releitura do texto e a elaboração de estratégias de resolução a partir de discussões entre eles, evitando apresentar respostas prontas. 
Observamos então, que através dessas orientações, os alunos começaram a adotar um novo comportamento durante o desenvolvimento do trabalho, de tal forma que realizavam a leitura do texto com mais atenção e dialogavam entre si sobre a melhor estratégia de resolução das questões por intermédio do trabalho colaborativo. Por conseguinte, a sequência permitiu romper com a lógica de aprendizado estabelecida na metodologia tradicional pautada na definição, exemplos e exercícios em que o aluno recorre logo ao professor quando surgem as primeiras dificuldades.

Um aspeto relevante do trabalho desenvolvido diz respeito à diversidade de registros gráficos, simbólicos ou em linguagem natural que foram utilizados pelos alunos durante a realização das atividades, pressupondo que só é possível ter acesso ao raciocínio do aluno a partir dessas representações e reconhecendo que o modo como o aluno representa um objeto matemático, pode interferir na sua aprendizagem. Assim, a partir da análise dos registros semióticos fornecidos pelos alunos, verificamos uma evolução gradativa questão a questão, tanto nas representações gráficas quanto nas representações algébricas referentes, favorecendo o desenvolvimento de sua capacidade de se expressar matematicamente e de sua aprendizagem, considerando que em geral, os alunos conseguiram realizar as transformações por conversão e por tratamento entre os registros gráficos, registros algébricos e os registros em língua natural.

A atividade possibilitou perceber que a matemática não se limita à sala de aula e que há muito desse conhecimento na pesca artesanal, a exposição da rede de pesca na sala de aula como elemento motivador que facilitou a compreensão das questões; as atividades desenvolvidas mostraram a importância da pesca artesanal para a economia do município; as atividades favoreceram o diálogo em casa sobre as relacionadas à pesca artesanal que estavam sendo desenvolvidas em sala de aula.

Ponderamos que esta pesquisa ficou longe de esgotar as possibilidades de aprender e ensinar matemática a partir de situações relacionadas a práticas específicas, como da pesca artesanal, e, nessa perspectiva pretende estimular o desenvolvimento de outros estudos que utilizem a articulação entre teorias como da Etnomatemática e Registro de Representação Semiótica.

\section{Referências}

ALMEIDA, Loudes Werle de; SILVA, Karina Pessôa da; VERTUAN, Rodolfo Eduardo. Modelagem Matemática na Educação Básica. 1a. ed. São Paulo: Contexto, 2016.

ASSUNÇÃO, Carlos Alberto Gaia; Ecologia de um saber matemático em um centro familiar de formação por alternância (CEFFA): O Método de Redução à Unidade nas Praxeologias da Escola CEPE: Dissertação de Mestrado. Belém - PA: Universidade Federal do Pará - UFPA, 2012. $118 \mathrm{p}$.

BERND, Arthur Barcellos. Registros de Representações Semióticas e a utilização de ambiente de geometria dinâmica na aprendizagem de conceitos de Geometria Analítica. Revista RENOLE, v. 14, n. 2, 2016.

D'AMBRÒSIO, Ubiratan. Etnomatemática: Arte ou técnica de explicar e conhecer. São Paulo: Editora Ática, 1990. 
D'AMBRÒSIO, Ubiratan. Educação pra uma sociedade em transição. 2a. ed. Campinas: Papirus, 2001.

D'AMBRÒSIO, Etnomatemática: Elo entre as tradições e a modernidade. 2a. ed. Belo Horizonte: Autêntica, 2002. (Coleção Tendências em Educação Matemática).

D'AMBRÒSIO, Ubiratan. Educação matemática: da teoria à prática. 10 ed. Campinas, SP: Papirus, 2003.

D'AMBRÒSIO, Ubiratan. Um enfoque transdisciplinar à educação e à história da matemática. In: BICUDO, Maria Aparecida Viggiani e BORBA, Marcelo de Carvalho (Orgs.). Educação matemática: pesquisa em movimento. São Paulo: Cortez, 2004.

D'AMBRÒSIO, Ubiratan. Etnomatemática: Elo entre as tradições e a modernidade. 2a. ed. Belo Horizonte: Autêntica, 2005.

D'AMORE, Bruno; PINILLA, Martha Isabel Fandino; IORI, Maura. Primeiros Elementos de Semiótica: Sua presença e sua importância no processo de ensino-aprendizagem da matemática. 1 ed. São Paulo: Editora Livraria da Física, 2015.

DUVAL, Raymond. Écarts sémantiques et chhérence mahtématique. Annales de Didactique et de Siences Cognitivas. v. 1, p. 7-25, 1988.

DUVAL, Raymond. Semiósis e Pensamento Humano: Registros semióticos e aprendizagens intelectuais. 1 ed. São Paulo: Livraria da Física, 2009. 120 p.

DUVAL, Raymond. Registros de representação semiótica e funcionamento cognitivo do pensamento. Revista Eletrônica de Educação Matemática, v. 7, n. 2, 2012.

FACCO, Sonia Regina. Conceito de Área Uma proposta de ensino-aprendizagem: Dissertação de Mestrado. São Paulo - SP: Pontifícia Universidade Católica - PUC - SP, 2003. $185 \mathrm{p}$.

GIARDINETTO, José Roberto Boottger. Matemática escolar e matemática da vida cotidiana. Campinas, SP: Autores Associados, 1999.

GIL, Antônio Carlos. Métodos e Técnicas de Pesquisa Social. 6 ed. São Paulo: Atlas, 2008.

LEÓN, Juan José Díaz Díaz; MAYORGA, Marco Antonio Soto; SÁNCHEZ, Adriana Martínez. Razonamiento Proporcional Intuitivo en Alumnos de Primaria y Secundaria. Revista Interamericana de Psicología, v. 41, n. 3, p. 371-378, 2007.

MIGUEL, Antônio; MENDES, Iran Abreu. Mobilizing in mathematics teacher education: memories, social practices, and discursive games. ZDM Mathematics Education, v. 42, p. 381-392, 2010.

PINHEIRO, Tássia Cristina Da Silva. Análise de registros de representação semiótica em uma atividade matemática com ribeirinhos muanenses: Dissertação de Mestrado. Belém - PA: Universidade do Estado do Pará - UEPA, 2015.

PINHEIRO, Tássia Cristina Da Silva; ALVES, Fábio José Da Costa; SILVA, Maria Do Perpétuo Socorro Cardoso Da. Aprendizagem matemática no contexto educacional ribeirinho: a análise de registros de representação semiótica em atividade de modelagem matemática. Revista Brasileira de Estudos Pedagógicos - RBEP, v. 97, n. 246, p. 339-355, 2016. 
SANTOS, José Nazareno Araújo Dos; BASTOS, Ana Paula Vidal. Inovações e mudanças na realidade amazônica: o caso da pesca do município paraense de Vigia de Nazaré. Novos Cadernos NAEA, Belém - PA, v. 10, n. 2, p. 49-66, 2008.

SEVERINO, Antônio Joaquim; Metodologia do Trabalho Científico - 23 ed. Rev. e atual. São Paulo: Cortez, 2017.

SHONARDIE, Belissa. Modelagem Matemática e Introdução da Função Afim no Ensino Fundamental: Dissertação (Mestrado em Ensino de Matemática). Porto Alegre: Universidade Federal do Rio Grande do Sul, 2011. 